\title{
Exploring medical students' professional identity formation through written reflections during the COVID-19 pandemic
}

\author{
Ardi Findyartini, ${ }^{1,2}$ Dewi Anggraeni, ${ }^{2}$ Joseph Mikhael Husin, ${ }^{1}$ Nadia Greviana ${ }^{1,2}$ \\ ${ }^{1}$ Medical Education Center, Indonesia Medical Education and Research Institute (IMERI); \\ ${ }^{2}$ Department of Medical Education, Faculty of Medicine, Universitas Indonesia
}

Acknowledgements: The authors would like to acknowledge all medical students who wrote their reflections following the completion of the COVID-19 module in this study and particularly thank those whose written reflections were further analyzed.

Correspondence: Ardi Findyartini, Medical Education Center, Indonesia Medical Education and Research Institute (IMERI), Department of Medical Education, Faculty of Medicine, Universitas Indonesia, Salemba 6, Central Jakarta.

Tel.: +62213901814

E-mail: ardi.findyartini@ui.ac.id, findyartini@yahoo.com

Key words: Professional identity formation; undergraduate; medical students; written reflections; COVID-19.

Contributions: AF led the study, completed data analysis, and led the manuscript development. All authors approved the final version of the manuscript. DAK was involved in the data collection, completed data analysis, and contributed to the manuscript development. All authors approved the final version of the manuscript. JMH was involved in data analysis and contributed to the manuscript development. All authors approved the final version of the manuscript. NG led the data collection, completed data analysis, and contributed to the manuscript development. All authors approved the final version of the manuscript.

Ethics approval and consent to participate: All participants in this study approved of and provided their verbal consent for the authors to analyse their reflections. The verbal consent was aimed to encourage free expression of the participants' reflections. The participants were

This article has been accepted for publication and undergone full peer review but has not been through the copyediting, typesetting, pagination and proofreading process, which may lead to differences between this version and the final one. Please cite this article as doi: 10.4081/jphr.2020.1918 
informed that their participation was completely voluntary and that the authors would ensure the confidentiality of the data provided in any of the reports that resulted from this study. The study protocol, including the use of verbal consent, was approved by the Research Ethics Committee of the Faculty of Medicine, Universitas Indonesia (Number KET 497/UN2.F1/ETIK/PPM.00.02/2020).

Availability of data and materials: The datasets generated and/or analysed during the current study are not publicly available due to conditions of participants' consents but are available from the corresponding author on reasonable request.

Funding: The study was funded by Universitas Indonesia (Grant number: NKB1525/UN2.RST/HKP.05.00/2020). The funding body has no role in the design of the study and collection, analysis, and interpretation of data and in writing the manuscript.

Conflict of interest: The authors declare no conflict of interest.

\title{
Significance for public health
}

The COVID-19 pandemic has caused disruptions for nearly everyone; this includes medical students affected by major changes to medical school curricula. The development of professionalism and Professional Identity Formation (PIF) among students is a critical aspect of undergraduate medical curriculum; it significantly impacts students' future careers as patient care providers. By identifying students' adaptation processes in facing the crisis, medical schools can provide appropriate support for students in their PIF. Students' contributions to preventing COVID-19 transmission in their own environment and the wider community, through their active engagement (such as via social media), is an essential PIF process for both preclinical and clinical students.

\begin{abstract}
Background

Disruptions due to the COVID-19 pandemic have forced medical schools around the world to adapt. Major changes in curriculum delivery during the pandemic have impacted medical students' professional development. We assess undergraduate medical students' adaptations and Professional Identity Formation (PIF) by exploring their written reflections.
\end{abstract}




\section{Methods}

This phenomenology study analyzes undergraduate medical students' written reflections. We perform a thematic analysis to identify emerging themes.

\section{Results}

We purposively selected 80 written reflections, considering the students' year of study, gender, GPA, and education stage (preclinical or clinical). Three themes emerged: students' adaptation processes and coping strategies in facing the pandemic; their adaptation processes for learning; and their perceived roles as medical students during the pandemic.

\section{Conclusions}

Adaptive coping mechanisms were implemented by medical students in this study. The socialization processes that promote professional identity formation may change due to the tremendous disruption wrought by the pandemic; this has prompted our investigation of students' roles and various ways of interacting with role models. We highlight the importance of the medical school supporting students' adaptations and professional identity formation during this pandemic.

\section{Background}

The COVID-19 pandemic, which began in Wuhan, China, in late 2019, has seriously disrupted the daily lives of people around the world. Medical schools have adapted by moving teaching and learning to online platforms ${ }^{1,2}$ and rescheduling, postponing, or modifying clinical rotations for undergraduate medical students while maintaining strong restrictions. The implementation and requirements of assessments have also been modified. ${ }^{3}$ Some medical schools have attempted to provide content enrichment around COVID-19 for medical students. ${ }^{4}$ All of these attempts require strong leadership and coordinated responses by a pandemic response team. ${ }^{5}$

There is a risk that some cohorts of medical students will not receive adequate real patient exposure during this pandemic due to current clinical rotation arrangements, which tend to limit undergraduate students involvement. ${ }^{6}$ However, online learning has facilitated knowledge acquisition for medical students through asynchronous or synchronous learning activities. $^{7}$ Online learning has become the core learning mode during the pandemic. Online learning for medical students may require further adaptation to foster the mastery of psychomotor skills. For students in their clinical year, experiential learning through real patient exposure has historically been one of the most important learning strategies. ${ }^{8}$ 
A critical aspect of the undergraduate medical curriculum is the professional development of medical students. Therefore, the major pandemic-induced changes in curriculum delivery should encourage a further appraisal of their impact on medical students' professional development. Professionalism is the practice of providing excellent, ethical, and altruistic patient care. ${ }^{9}$ It consists of five key aspects: reliability; adherence to ethical principles; effective interactions with patients, their family members, and their significant others; effective interactions within the healthcare system; and a commitment to improving competence for oneself, others, and the healthcare system. ${ }^{10}$

Professional Identity Formation (PIF) has been recognized as a fundamental concept in professional development. ${ }^{11}$ Professional identity is defined as "the attitudes, values, knowledge, beliefs and skills shared with others within a professional group."12 JarvisSelinger et al. further describe identity formation as an adaptive and developmental process at both the individual and collective levels that involves psychological evolution and socialization - a person becomes accountable for participation and may enact certain roles in a certain community of professionals. ${ }^{13}$ This development occurs during medical education and training and progresses into a student's professional life. ${ }^{14}$

The many challenges in this difficult time may impact medical students' professional development and PIF. ${ }^{15}$ The complexity of conducting medical education during this pandemic, especially in clinical settings, may cause medical students to feel powerless. ${ }^{16}$ The critical process in PIF is socialization, which incorporates multiple factors, such as the individual students (e.g., existing personal identity), the learning environment, role models and mentors, clinical/nonclinical experiences, formal teaching and assessment, symbols and rituals, and attitudes towards and treatment of the students by patients, health care professionals, and the public. ${ }^{17}$ Changes in one or more of these factors may affect the socialization process and professional identity formation among medical students. These changes are likely to occur in the current pandemic. Further adaptations to support medical students have been initiated by medical schools. For example, a medical school in the US has reported the need to adjust curriculum components of PIF to support students' learning needs during this crisis, because students simultaneously feel uncertain about their roles and eager to contribute and also may be experiencing feelings of isolation, helplessness, and fear. ${ }^{18}$ Considering the need to support medical students in their adaptations during this difficult time, we assess these adaptations through a PIF lens by exploring undergraduate medical students' written reflections. This study was approved by the Research Ethical Committee of 
the Faculty of Medicine Universitas Indonesia (Number: KET-

497/UN2.F1/ETIK/PPM.00.02/2020).

\section{Design and Methods}

\section{Context}

This study was performed at the Undergraduate Medical Program, Faculty of Medicine, Universitas Indonesia (FMUI), which has a 5.5-year curriculum. Students complete a preclinical stage in 3.5 years and continue on to a clinical stage for 2 years. Professional development, including professional identity formation, has been integrated into the curriculum of both the preclinical and clinical stages. A specially designed longitudinal course has been implemented to facilitate students' professional development. This course focuses on students' capacity for self-reflection, empathy, communication skills, cultural competence, and knowledge about practices related to ethical dilemmas and other humanistic and professionalism issues. During the pandemic, the course has been adjusted, minimizing students' direct interactions with teachers as role models and their involvement in both community-based activities (e.g., activities involving vulnerable populations) and clinical activities (e.g., involvement in teaching hospitals). Students have been given access to an open online course discussing critical objectives related to the COVID-19 pandemic. They have been encouraged to summarize their understanding by producing public health education materials in groups. The FMUI teaching hospital where students conduct their clinical rotations is located in Central Jakarta, which had become an epicenter of COVID-19 transmission in Indonesia when we performed this study.

\section{Design}

This phenomenology study utilizes written reflections to examine respondents' experiences and thoughts. ${ }^{19}$ A phenomenological study generally aims to understand the meaning and significance of the lived experiences of multiple individuals. ${ }^{20}$

\section{Data collection}

Our study involves undergraduate medical students in years 2, 3, and 5, with 250 students per cohort; thus, the study population includes students from both the preclinical and clinical stages. Students were asked to write a 500-800 word written reflection (in either Indonesian or English) following the completion of a COVID-19 open online course. The reflections address the following questions: i) How have you felt during the COVID-19 pandemic? What 
have you done to adapt to this current situation? How do you adapt to the current situation? Please describe this further; ii) As a medical student, do you believe that you can do something to address this pandemic? What have you done? What do you think are the potential roles of medical students during this pandemic?

Students submitted their written reflections on the provided learning management system. We purposively selected the reflections based on the students' year of study, gender, GPA, and stage (preclinical vs. clinical), aiming for data saturation. Consent for further analysis was granted by the students whose written reflections were selected. Data were collected during the period in which students accessed the provided open online course regarding COVID-19 (April $20^{\text {th }}$ to May 20 ${ }^{\text {th }}, 2020$ ).

\section{Data analysis}

We performed a thematic analysis to identify emerging themes and subthemes relevant to the research question. Two authors (AF and NG) completed independent analyses on two similarly written reflections before agreeing on themes and subthemes. All authors conducted the thematic analysis based on this agreement. Any disagreements on themes and subthemes were discussed by all authors.

\section{Results}

Written reflections were purposively selected using a maximum variation sampling method that considered the students' year of study, gender, GPA, and stage (preclinical or clinical). Data saturation occurred with the analysis of 80 written reflections. Table 1 describes the number of students in each category whose reflections were assessed in our study. Three major themes emerged from the analysis: students' adaptation processes and coping strategies in facing the pandemic; their adaptation processes for learning; and their perceived roles as medical students during the pandemic (Table 2).

\section{Students' adaptations and coping strategies in facing the pandemic}

The challenges arising during the pandemic in Indonesia - a resource-limited country with diverse cultures and socioeconomic backgrounds - also created awareness and empathy among students towards their surroundings. Students empathized with various roles in their community despite concerns about their own health and that of their loved ones. Some students also remarked on certain lifestyle changes in society following the pandemic. Students also tried to have a positive mindset in facing the uncertain situations. 
"Some people may feel helpless from being stuck at home and feeling like they can't do anything to take part in the solution of this situation, while others may feel sad about having their plans cancelled due to the pandemic, their jobs lost due to businesses closing down, or their family members who are sick and at risk of death due to the disease." (LW, third preclinical year)

"I tried to see the silver lining, the positive changes during this pandemic. The community was more aware of their health. Society viewed medical authorities better - in the past, sometimes medical authorities were blamed or viewed as scapegoats. People participated in crowdfunding, taking care of each other." (AZ, second clinical year)

In facing such a dynamic situation during the pandemic, students in both the preclinical and clinical stages decided to follow the COVID-19 protocols from the authorities. Preclinical students added that they tried to refer to health information only from reliable and trusted sources.

"I tried my best to follow through the authorities' protocol. I realized that every single person has to actively participate to reduce the transmission [of COVID-19]." (AH, second clinical year)

"I try to keep up to the newest information regarding COVID-19 and shared the crucial information with people around me; however, I make sure that the source is credible." (MRe, second preclinical year)

Students tried to stay connected both spiritually and socially. Social connections were crucial to getting through the pandemic.

"I am trying to convince myself that it happens and will also end because of God Almighty's will. With that in mind, I have found serenity and can accept this situation with sincerity" (RAT, second clinical year) 
"Not only that, staying with my family helps my psychological state. I feel safer and calmer to go through this pandemic." (I, second preclinical year)

\section{Students' adaptation processes for learning}

The sudden changes in the teaching/learning process due to the pandemic pushed students to adapt quickly. Students acknowledged their worries about how the pandemic might affect their education and skills acquisition. Students reported a lack of clinical skills obtained during the fully online learning period; students in the clinical stage were especially worried about their lack of interaction with real patients.

"As a clinical year student, theoretical knowledge and clinical skills are equally important aspects of learning. Before the pandemic, both my theoretical knowledge and clinical skills were gained in close proximity. This allowed me to better integrate both knowledge and skills in order to make it easier to internalize it; this may be difficult to do during this time, when we were retracted from our clinical practice and focused mainly on the knowledge aspect." (FA, second clinical year)

"There is quite a bit of confusion on our practical sessions, which [usually] involves the dry and wet lab. Although we have been given resources to read and watch, I still think that there is no replacement for a practical session because knowledge is attained from our experience in performing it, especially with anatomy sessions. ” (I, second preclinical year)

However, they also weighed the risks and benefits of important aspects of the pandemic situation. Students were aware of their lack of knowledge regarding COVID-19, their level of competence, the lack of Personal Protective Equipment (PPE), and other important issues that would have affected their safety and their patients' safety during the pandemic.

"I understand that the situation in the hospital during this pandemic is not conducive to optimal clinical learning. Residents and consultants would certainly be preoccupied with services for COVID-19 patients so that the transfer of knowledge would be limited. I understand that the availability of PPE in hospitals throughout Indonesia was very limited - of course this is an important concern and a primary reason that we could not remain in hospital for clinical practice. If we forced 
ourselves to help in the frontline without PPE, my friends and I would have violated bioethics principles, especially beneficence and justice, because we could be a medium of transmission to patients and people around us. The most dangerous thing is, of course, we could be at risk of contracting [the virus]." (MH, second clinical year)

"Truthfully, I should have probably paid more attention to the COVID-19 outbreak while it was still an issue in China. Academic life has kept me away from this news, and even when the virus started to spread to neighboring countries, I did not care much. It felt like I had a lot more important tasks to attend to, and paying attention to the people in need was too much effort." (C, second preclinical year)

Despite the worries, anxiety, and recognized risks, students also identified opportunities for learning and self-development. Students identified new roles for future medical doctors that they rarely thought about prior to this pandemic. They identified their knowledge limitations regarding how to manage new emerging infectious diseases, because the COVID-19 pandemic showed how important this knowledge will be to future medical doctors. Opportunities to participate in research about COVID-19 were also highlighted by students.

"I had the thought that this pandemic could be an opportunity to conduct research and publish a paper. I imagined that it could be in the form of collaboration between clinicians and students. My clinical teachers may be too busy to have time to collect data, make their writings, and publish because they are directly involved in the field. Thus, students can actually help in conducting the study." (SI, second clinical year)

"I noticed that medical practitioners everywhere were not ready to face this pandemic. As a future practitioner, I need to explore more about what I will do in such situations." (HA, second clinical year)

Students also reported adapting to the sudden shift in the teaching and learning processfrom offline and/or blended learning to fully online learning. Some students appreciated the online learning method, which provided self-paced learning, time to rest from the busy academic life they had prior to the pandemic, and flexibility to do other things they loved. 
However, they also noted the importance of self-discipline and the ability to self-regulate their learning in following this new learning method.

"The self-paced module really challenged my adult learning ability because we are not used to following a module without prior tight scheduling." (DA, second clinical year)

“Personally, I feel that I get chances to practice my hobbies that I haven't been able to do lately, such as doing sports and learning many things other than medicine."

(RL, third preclinical year)

However, students also addressed some challenges in conducting fully online learning, such as an overflow of information. Thus, preparedness, discipline, and maintaining a routine were important. Students wrote that maintaining intensive communication with the education program organizers and teachers helped them. Peers also played important roles during the teaching/learning adaptation process. Students managed to share each other's learning pace, and some even managed to conduct virtual group learning to support each other.

"We initiated a study group to prepare for the board exam while waiting for our clinical rotation to be restarted. We browsed and shared questions, discussed the questions in groups, and invited our clinical teachers or seniors to help us with clarification sessions." (SI, second clinical year)

"I asked my friends about how they are doing during the pandemic so I can consciously justify my actions of losing productivity. From the answers that I get, it turns out that they are doing things similar to what I am doing, so I feel like my actions have been justified and I didn't feel bad afterwards." (I, second preclinical year)

\section{Students' perceived roles as medical students during the pandemic}

Both preclinical and clinical students believed they had roles to play in providing public education and awareness regarding COVID-19 (both directly and through the use of social media) to help prevent the spread of COVID-19. Students also highlighted their roles in 
increasing public empowerment to educate the community with updated knowledge regarding COVID-19.

"We can educate others indirectly through social media as part of disseminating valid information against the hoax that is spreading on social media, as people with a medical background who are often more trusted by our family and friends." (OEY, second clinical year)

"There are also rising numbers of fake news and hoaxes that circulate around regarding the various 'cures' that have been found, leading to more worry. Hence, we can break this chain by consoling our nearest and dearest, by not only telling them the most recent and most appropriate information but also by encouraging them to not spread the news further and then educating their friends as well. This way, the cycle of fake news and the spread of hoaxes can be significantly slowed down." (D, second preclinical year)

Some students also acknowledged their role in being directly involved in several volunteer activities, such as initiating crowd funding to provide PPE and nutrition for frontline workers. Students discussed their desires to directly serve on the front line as volunteers. They mentioned possible roles that did not require direct contact with COVID-19 patients, such as conducting contact tracing, providing indirect patient education, and monitoring asymptomatic patients during self-isolation through text-messages.

"I think students have the chance to help, both by telemedicine, such as a question/answer system through a hotline or call center, and by actively participating in medical services in outward or inward settings (but not obligatory to all students)." (SS, second clinical year)

"Medical students may be volunteering to contact asymptomatic patients during selfisolation periodically to help front liners." (AZ, second clinical year)

"I am involved in several volunteer activities that aim at mitigating the negative impacts of COVID-19 in Indonesia and also on an international scale. My primary 
focus is leading a team of 13 United Nations Online Volunteers working together on an international COVID-19 relief project." (EY, third preclinical year)

Although some clinical-year students participated in volunteer activities, students highlighted the importance of guidance from policymakers in managing students' volunteer activities for mitigating the pandemic; this is currently lacking.

"The role of clinical-year students in mitigating COVID-19 is assessed individually. The urge to help stems from students' desire to help and is not coordinated by the government or institution; for example, many students initiate crowdfunding to help front liners individually." (NR, second clinical year)

"The government should integrate all departments' volunteer programs so the resources can be obtained from one source. I hope this integration has a positive impact in terms of preventing disease transmission and utilizing human resources." (FA, second clinical year)

Although students perceived their roles as educators and volunteers, they faced professionalism dilemmas in fulfilling these roles.

"Sometimes, although we tried to help in providing public education, we are still just students, who are considered to not know much. This is one obstacle that caused some of my friends to not really want to help during pandemic. If there is trust and good collaboration, we can help each other and lift some medical staffs' burden. Nevertheless, I will try to help as much as I can." (AN, second clinical year)

\section{Discussion}

This study explores undergraduate medical students' adaptations, professional identity formation, and related factors during the COVID-19 pandemic. We used written reflections to give students the opportunity to express their thoughts and insights about the questions in their own words. In this way, we provided a safe environment for students to elaborate on whatever they wanted, without the fear of being judged. Students were also informed that their written reflections did not have any consequences for their grades. This approach was deemed important in this study, given the hierarchical and masculine culture in Indonesia, in 
which students may hesitate to express their weaknesses, vulnerabilities, and doubts. ${ }^{21,22}$ Studies have suggested that reflection may encourage students to think consciously about their professional identity development. ${ }^{23,24}$ Discussing narrative reflections encourages students to analyze their current identity (e.g., "I am a student"), their future identity (e.g., what kind of doctor they want to be), and their experiences of identity dissonance. ${ }^{17,25}$ The first theme that emerged in our study was how students have been adapting during the pandemic. Medical students from both the preclinical and clinical stages have attempted to adapt in various ways. Medical students have been described as having heavy burdens in their studies, which may lead to burnout, ${ }^{26}$ the likelihood of burnout is higher for students with less internal motivation. ${ }^{27}$ The current epidemic presents a very uncertain situation to undergraduate medical students. The most prevalent question, which is difficult to respond to, was, "How long should these adaptations be in place?" Reflecting on the experiences shared in this study, most students in both preclinical and clinical years seemed to have adaptive coping mechanisms derived from both problem-focused strategies (e.g., adapting to a fully distance-learning approach, seeking peer support, and intensifying communication with course organizers) and emotion-focused strategies (e.g., positive reframing of what was happening, having closer interactions with family, and seeking spiritual support). ${ }^{28,29}$ Based on the Kübler-Ross Change Curve, ${ }^{30}$ at the time of this study, most students had reached the "experiment" stage (adopting new attitudes and behavior in the current situation) or the "decision" stage (exploring more positive ways to deal with the current difficulties).

However, some students still expressed their anger and frustration regarding the current changes and uncertainties. Therefore, students at different stages of adaptation will require appropriate support from the medical school.

Regarding the second theme (students' adaptations for their learning processes), students in the clinical years seemed to experience greater challenges than those in the preclinical years. Students in the clinical stage reported challenges stemming from their inability to participate in direct patient management due to safety considerations. Students felt disadvantaged; they were aware that learning directly with patients is vital to achieving competence and developing their professional identity. Contact with real patients provides rich learning experiences that contribute to the development of their cognitive and metacognitive skills. Real patient exposure also gives students authentic experience as physicians who must deal with patients' problems comprehensively. ${ }^{8}$ In addition, real practice in a clinical setting also enables direct observation of student performance, which considers sociocultural factors such 
as autonomy in learning and efficiency in health care provision. ${ }^{31}$ Through supervised, real patient exposure in clinical settings, students learn how to act as a medical doctor. ${ }^{17}$ However, assigning students to clinical practice during this pandemic must be considered from an ethical perspective. In addition to the risks to the students' safety, they are not yet fully competent as medical doctors. Consequently, they may be less prepared for participation on the front line, which could endanger the students themselves, the patients, and other health professionals. ${ }^{32}$ Arguably, all of these concerns can be mitigated by providing adequate PPE and knowledge about preventing COVID-19 infection transmission. ${ }^{33}$ Students' assignments in clinical rotations could be voluntarily conducted and the rotations could be optimized in non-COVID-19 clinical care. This dilemma is probably best discussed openly with the students; their new insights on this issue may be critical for their professional identity formation. ${ }^{18}$

These first two themes (students' adaptations and coping strategies in facing the pandemic and students' adaptation processes for their learning) mostly concern students' internal processes, by which they challenge their existing identities: who they are, how they cope, what their characteristics are. ${ }^{17}$ The current pandemic, which has profound implications for both daily life and medical education, constitutes a major disruption that affects the socialization process of medical students. As highlighted by Cruess et al., socialization (involving role models and mentors, clinical and non-clinical experiences, and a community of practice) is a core process in PIF. ${ }^{17}$ Our study suggests two plausible changes in the socialization process during the pandemic. First, as highlighted by the students, the current pandemic has precipitated potentially life-changing experiences for each individual. The students saw themselves not only as young adults trying to cope, but also as medical students. Once they had adapted to the new situation, they moved closer to identifying their roles and determining what they could contribute in this difficult situation. Both preclinical and clinical students strongly agreed that volunteer work and public health education using valid and reliable information were the least they could do. Students in the clinical stage also suggested potential roles in non-COVID-19 and COVID-19 management in the teaching hospital or in the community, with precautions in place based on their competencies and safety. Second, the use of online learning has changed how students interact with their mentors and role models, as well as with patients and other health professionals. Although the students in our study felt that the clinical teachers were available for them-for example, to discuss clinical cases and teach procedural knowledge online — such online platforms may be inadequate for providing real human interactions and empathy development. ${ }^{34}$ 
According to the adapted Kegan's stages of PIF, ${ }^{17}$ the students in our study showed two levels of development. The preclinical students were at the "imperial" stage, which is characterized by having an interest in others while their own needs still predominate, being motivated to follow rules, and having emotions that can overwhelm their reasoning ability. Clinical students seemed to have reached the "interpersonal" stage, where they have multiple perspectives, are able to disregard self-interest, and are concerned about how they are perceived by others. In other words, these students are almost able to assume professional roles, share obligations, and generally make correct decisions. ${ }^{17}$ This is seen in their reflections: while both preclinical and clinical students were anxious and confused, especially in the early stage of the pandemic, concerns about important issues and the roles of medical students during the pandemic were shared more often by clinical students.

This study also shows that the dynamic changes in the socialization process during this pandemic may not disrupt PIF among medical students. In a previous study conducted among preclinical medical students in the same setting before the pandemic, the preclinical students also reflected characteristics of the imperial stage. ${ }^{22}$ Our study, however, underlines that the adaptations and changes in the socialization process amidst a major disruption should be recognized in medical school. Therefore, supporting students through guided reflection and mentoring is necessary during this period. ${ }^{18}$ These explicit processes can reveal the development of professional identity at the subconscious level, ${ }^{13,23}$ which helps students reshape and negotiate PIF further. Learning activities that enable students to discuss their current roles during the pandemic, ethical reasoning on the most appropriate venues for volunteering, and wellbeing issues are recommended during the pandemic. ${ }^{18}$ The use of a reflective e-portfolio with guided reflection (involving mentors who facilitate further discussions and provide feedback for students' reflection) may facilitate this process during this era of physical distancing. ${ }^{35}$

Finally, we are aware of our study's limitations. First, this study was conducted in only one medical school; hence, the results have limited generalizability. However, the COVID-19 pandemic and its consequences on medical education have been global. Therefore, our findings - sourced from students' reflections on their adaptations and PIF during the pandemic - may be useful in other undergraduate medical education settings. In addition, the inclusion of written reflections from preclinical and clinical students was deemed important for exploring possible differences and optimizing the relevance of this study. Second, we have analyzed perspectives from students' written reflections at a single point in time. Consequently, the results cannot reveal the process of or changes in PIF. However, we were 
able to differentiate levels of PIF according to Kegan's development (as adapted in Cruess et $a l{ }^{17}$ ) and discuss possible changes in the socialization process.

\section{Conclusions}

The current pandemic has generated many disruptions and challenges, which have compelled medical students to rethink and reflect upon what they have been learning. This study assesses medical students' adaptations through a PIF lens, identifying three primary themes: students' adaptation processes and coping strategies in facing the pandemic; their adaptation processes for their learning; and their perceived roles as medical students during this pandemic. Despite the challenges they faced at the early stage, the students in our study seemed able to employ adaptive coping mechanisms. Clinical students appear to encounter greater challenges in adapting their learning than preclinical students, due to the temporary suspension of clinical rotations during the pandemic, which has prevented clinical students from having real clinical experience. Students at both stages have achieved different levels of PIF, which may not be different from the levels that would have been reached in a nonpandemic situation. However, the socialization process that influences PIF may change due to the major disruptions in the education system, which have led to strong reflections on students' roles and to different ways of interacting with their role models and mentors through online learning platforms. Overall, we highlight the importance of support from the medical school for students' adaptations and professional identity formation, which may include mentoring and the creation of environments where students can express their concerns, doubts, and dilemmas. We recommend these efforts during this difficult situation to assure adequate facilitation of medical students' professional development during their medical training.

\section{References}

1. Goh PS, Sandars J. A vision of the use of technology in medical education after the COVID-19 pandemic. MedEdPublish 2020;9:49.

2. Samarasekera DD, Goh DLM, Yeo SP, et al. Response and lessons learnt managing the COVID-19 crisis by School of Medicine, National University of Singapore. MedEdPublish 2020;9:92.

3. Boursicot K, Kemp S, Ong TH, et al. Conducting a high-stakes OSCE in a COVID-19 environment. MedEdPublish 2020;9:54. 
4. Buckley MRF. A COVID-19 curriculum. Boston (MA): Harvard Medical School. Accessed 2020 Jun 26. Available from: https://hms.harvard.edu/news/covid-19curriculum.

5. Ashokka B, Ong SY, Tay KH, et al. 2020. Coordinated responses of academic medical centres to pandemics: sustaining medical education during COVID-19. Med Teach 2020;42:762-71. doi.org/10.1080/0142159X.2020.1757634

6. Mian A, Khan S. Medical education during pandemics: a UK perspective. BMC Med 2020;18:100.

7. Pei $\mathrm{L}, \mathrm{Wu} \mathrm{H}$. Does online learning work better than offline learning in undergraduate medical education? A systematic review and meta-analysis. Med Educ Online 2019;24:1666538.

8. Bell K, Boshuizen HPA, Scherpbier A, Dornan T. When only the real thing will do: junior medical students' learning from real patients. Med Educ 2009;43:1036-43.

9. Cruess SR, Cruess RL. Understanding medical professionalism: a plea for an inclusive and integrated approach. Med Educ 2008;42:755-77.

10. Wilkinson TJ, Wade WB, Knock LD. A blueprint to assess professionalism: results of a systematic review. Acad Med 2009;84:551-8.

11. Irby DM, Hamstra SJ. Parting the clouds: three professionalism frameworks in medical education. Acad Med 2016;91:1606-11.

12. Adams K, Hean S, Sturgis P, Macleod Clark J. Investigating the factors influencing professional identity of first year health and social care students. Learn Health Soc Care 2006; 5:55-68.

13. Jarvis-Selinger S, Pratt DD, Regehr G. Competency is not enough: integrating identity formation into the medical education discourse. Acad Med 2012;87:118590.

14. de Lasson L, Just E, Stegeager N, Malling B. Professional identity formation in the transition from medical school to working life: a qualitative study of groupcoaching courses for junior doctors. BMC Med Educ 2016;16:165.

15. Eva KW. Strange days. Med Educ 2020;54:492-3.

16. Helmich E, Diachun L, Joseph R, et al. 'Oh my God, I can't handle this!': trainees' emotional responses to complex situations. Med Educ 2018;52:206-15. 
17. Cruess RL, Cruess SR, Boudreau JD, et al. A schematic representation of the professional identity formation and socialization of medical students and residents: a guide for medical educators. Acad Med 2015;90:718-25.

18. Stetson GV, Kryzhanovskaya IV, Lomen-Hoerth C, Hauer KE. Professional identity formation in disorienting times. Med Educ 2020;54:765-6. doi:10.1111/medu.14202.

19. Finlay L. 'Writing the pain': engaging first-person phenomenological accounts. IndoPacific J Phenomenol 2012;12:1-9.

20. Creswell JW, Poth CN. Qualitative inquiry and research design: choosing among five approaches. Los Angeles (CA): Sage; 2008. pp.57-8.

21. Hofstede G, Hofstede GJ, Minkov M. Cultures and organizations: software of the mind. New York (NY): McGraw-Hill; 2010.

22. Findyartini A, Sudarsono NC. Remediating lapses in professionalism among undergraduate pre-clinical medical students in an Asian institution: a multimodal approach. BMC Med Educ 2018;18:88.

23. Joseph K, Bader K, Wilson S, et al. Unmasking identity dissonance: exploring medical students' professional identity formation through mask making. Perspect Medical Educ 2017;6:99-107.

24. Clandinin J, Cave MT, Cave A. Narrative reflective practice in medical education for residents: composing shifting identities. Adv in Med Educ and Pract 2010;2:1-7.

25. Wong A, Trollope-Kumar K. Reflections: an inquiry into medical students' professional identity formation. Med Educ 2014;48:489-501.

26. IsHak W, Nikravesh R, Lederer S, Perry R, Ogunyemi D, Bernstein C. Burnout in medical students: a systematic review. Clin Teach 2013;10:242-45.

27. Felaza E, Findyartini A, Setyorini D, Mustika R. How motivation correlates with academic burnout: study conducted in undergraduate medical students. Educ Med J 2020;12:43-52.

28. Meyer B. Coping with severe mental illness: relations of the Brief COPE with symptoms, functioning, and well-being. J Psychopathol Behav Assess 2001;23:26577.

29. Cooper C, Katona C, Orrell M, Livingston G. Coping strategies and anxiety in caregivers of people with Alzheimer's disease: the LASER-AD study. J Affect Disord 2006;90:15-20. 
30. Kübler-Ross E. On death and dying. New York(NY): Scribner;1969.

31. Watling C, LaDonna KA, Lingard L, et al. 'Sometimes the work just needs to be done': socio-cultural influences on direct observation in medical training. Med Educ 2016;50:1054-64.

32. Whelan A, Prescott J, Young G, et al. Interim guidance on medical students' participation in direct patient contact activities: principles and guidelines. Washington DC. 2020

33. Miller DG, Pierson L, Doernberg S. The role of medical students during the COVID19 pandemic. Ann Intern Med 2020; doi:10.7326/M20-1281.

34. Lee J, Kim H, Kim KH, et al. Effective virtual patient simulators for medical communication training: a systematic review. Med Educ 2020;00:1-10.

35. Greviana N, Mustika R, Soemantri D. Development of e-portfolio in undergraduate clinical dentistry: How trainees select and reflect on evidence. Eur J Dent Edu 2020;24:320-7. 
Table 1. Numbers of students' reflections assessed.

\begin{tabular}{llccc}
\hline & & \multicolumn{3}{c}{$3.01-$} \\
Preclinical & Male & 4 & 8 & 7 \\
& Female & 4 & 8 & 8 \\
Clinical & Male & 1 & 8 & 11 \\
& Female & 0 & 10 & 11 \\
\hline
\end{tabular}


Table 2. Themes, subthemes, and total quotes.

\begin{tabular}{|c|c|c|c|}
\hline \multirow[t]{2}{*}{ Theme } & \multirow[t]{2}{*}{ Subthemes } & \multicolumn{2}{|c|}{ Total Quotes } \\
\hline & & $\begin{array}{l}\text { Clinica } \\
\text { l }\end{array}$ & $\begin{array}{l}\text { Preclinic } \\
\text { al }\end{array}$ \\
\hline \multirow{4}{*}{$\begin{array}{l}\text { Students' } \\
\text { adaptation } \\
\text { processes and } \\
\text { coping strategies }\end{array}$} & $\begin{array}{l}\text { Pandemic situation encouraged students' awareness } \\
\text { and empathy towards surroundings }\end{array}$ & 31 & 39 \\
\hline & $\begin{array}{l}\text { References to COVID- } 19 \text { protocols from the } \\
\text { authorities and information from reliable sources }\end{array}$ & 16 & 19 \\
\hline & Applying a positive mindset & 3 & 17 \\
\hline & Staying connected socially and spiritually & 14 & 14 \\
\hline \multirow{9}{*}{$\begin{array}{l}\text { Students' } \\
\text { adaptation } \\
\text { processes for } \\
\text { learning }\end{array}$} & $\begin{array}{l}\text { Acknowledgement of feelings, risks, and } \\
\text { opportunities }\end{array}$ & & \\
\hline & $\begin{array}{l}\text { Acknowledging worries and anxiety about the effects } \\
\text { of the pandemic on their study and skills }\end{array}$ & 39 & 14 \\
\hline & $\begin{array}{l}\text { Weighing the risks and benefits of important aspects } \\
\text { of the pandemic situation }\end{array}$ & 43 & 36 \\
\hline & $\begin{array}{l}\text { Identifying opportunities for learning and self- } \\
\text { development following the pandemic }\end{array}$ & 9 & 7 \\
\hline & $\begin{array}{l}\text { Adaptation to the shift in the teaching and } \\
\text { learning processes }\end{array}$ & & \\
\hline & Students appreciated the "new" learning method & 34 & 16 \\
\hline & Maintaining routine, preparedness, and discipline & 4 & 1 \\
\hline & $\begin{array}{l}\text { Maintaining intensive communication with the } \\
\text { education program organizers and teachers }\end{array}$ & 2 & 2 \\
\hline & Managing peer support & 1 & 2 \\
\hline \multirow{9}{*}{$\begin{array}{l}\text { Students' } \\
\text { perceived roles as } \\
\text { medical students } \\
\text { during the } \\
\text { pandemic }\end{array}$} & $\begin{array}{l}\text { Roles as community health educators and role } \\
\text { models }\end{array}$ & & \\
\hline & $\begin{array}{l}\text { Educating the community/surroundings directly } \\
\text { through role modeling }\end{array}$ & 21 & 30 \\
\hline & Optimizing social media to educate the community & 18 & 23 \\
\hline & $\begin{array}{l}\text { Providing the community with accurate information } \\
\text { and becoming the "myth and hoax busters" }\end{array}$ & 19 & 28 \\
\hline & $\begin{array}{l}\text { Increasing community empowerment to educate the } \\
\text { community with updated knowledge regarding } \\
\text { COVID-19 } \\
\text { Roles in serving the community }\end{array}$ & 0 & 6 \\
\hline & Direct involvement in volunteer activities & 21 & 22 \\
\hline & $\begin{array}{l}\text { Identifying possible roles in the frontlines without } \\
\text { direct contact with COVID-19 patients }\end{array}$ & 13 & 2 \\
\hline & $\begin{array}{l}\text { Importance of policy in managing students' } \\
\text { volunteer activities for mitigating the pandemic }\end{array}$ & 4 & 0 \\
\hline & $\begin{array}{l}\text { Professional dilemma in fulfilling the perceived } \\
\text { roles }\end{array}$ & 32 & 0 \\
\hline
\end{tabular}

